\title{
A EDUCAÇÃO INCLUSIVA NA PERCEPÇÃO DOS PROFESSORES DE QUÍMICA
}

\author{
Inclusive education \\ in trainee teachers' perception of licensed in Chemistry
}

\author{
Eveline Borges Vilela-Ribeiro ${ }^{1}$ \\ Anna Maria Canavaro Benite ${ }^{2}$
}

Resumo: O direito da criança e do adolescente é garantido desde a Declaração Universal dos Direitos Humanos, independente das condições físicas, intelectuais, sociais, emocionais ou linguísticas que possua. Esse é o princípio básico da educação inclusiva: as diferentes necessidades de aprendizagem dos sujeitos. E, sob a ótica da educação inclusiva, nos deparamos com o ensino de ciências, que defendemos para todos. Acreditamos que o lugar ideal de preparação do professor para a educação, inclusiva ou não, é a graduação. Por essa razão, foram investigadas as percepções sobre educação inclusiva de todos os professores formadores de um curso de licenciatura em Química de uma Instituição de Ensino Superior (IES) pública de Goiás, já que são esses que preparam os futuros professores e suas opiniões têm influência no currículo do curso. Constatou-se que os professores não se sentem, ainda, preparados para a inclusão, e que precisam adequar sua visão sobre educação inclusiva.

Palavras-chave: Formação de professores. Inclusão. Concepções.

Abstract: The right of children and adolescents to education is guaranteed since the Universal Declaration of Human Rights, independent of the physical, intellectual, social, emotional or language they posses. This is the basic principle of inclusive education, the different needs for learning. And from the perspective of inclusive education, we face the same for science education. We believe that the ideal place to prepare for the teacher education, inclusive or not, is the graduate. Therefore, we investigated the perception of inclusive education for all teacher trainers in a Chemistry course in a Public University in Goiás, as are these are the future teachers and their view has an influence on the curriculum of the course. It was found that teachers do not feel ready for inclusion and they need to adjust their views of inclusive education.

Keywords: Teachers' education. Inclusion. Conceptions.

\footnotetext{
${ }^{1}$ Licenciada em Química, mestranda em Educação em Ciências e Matemática. Docente, Universidade Federal de Goiás (UFG), Campus Jataí. Goiânia, GO, Brasil. <eveline_vilela@yahoo.com.br>

${ }^{2}$ Licenciada e Bacharel em Química, doutora em Ciências. Coordenadora, Laboratório de Pesquisas em Educação Química e Inclusão (LPEQI), Instituto de Química, UFG. Goiânia, GO, Brasil.

$<$ anna@quimica.ufg.br>
}

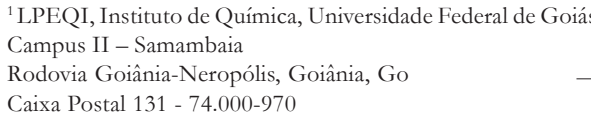




\section{Introdução}

O direito da criança e do adolescente à educação é garantido desde a Declaração Universal dos Direitos Humanos em 1948, independentemente das condições físicas, intelectuais, sociais, emocionais ou linguísticas que possua (UNESCO, 1994). Entretanto, apesar dos avanços acontecidos no âmbito da democratização da sociedade, a realidade aponta para a necessidade de ampliação dos espaços de socialização dos alunos em situação de deficiência (visuais, físicas, mentais, auditivas, múltiplas, desvios de conduta, superdotação ou altas habilidades).

A educação especial é definida no artigo 58 da Lei de Diretrizes e Bases brasileira (Lei no 9394/96), como "a modalidade de educação, oferecida preferencialmente na rede regular de ensino, para educandos portadores de necessidades especiais de ensino" (BRASIL, 1996, p. 31). Dessa maneira, o Estado recomenda duas questões principais: a primeira é que o aluno, em situação de deficiência, receba educação; a segunda é que essa educação seja preferencialmente oferecida em espaços de ensino regular. Só em Goiás, existem, aproximadamente, duzentos mil jovens em idade escolar e em situação de deficiência, sendo que desses, apenas 58 mil estavam matriculados nas escolas em 2006. Os dados da educação especial de Goiás revelam ainda uma realidade diferente da que é recomendada em lei, embora já tenham acontecido avanços: no ano de 2006, 49\% das matrículas de alunos especiais foram realizadas em estabelecimentos regulares de ensino, e $51 \%$ foram realizadas em estabelecimentos de ensino especial (BRASIL, 2006). Mais abrangente ainda é a educação inclusiva, que tem por definição que todos os alunos são especiais, e não só aqueles com algum tipo de deficiência, e, por esse motivo, a escola deve oferecer os melhores serviços possíveis a todos. O papel fundamental da educação inclusiva é oferecer escolarização a todas as pessoas que enfrentam algum tipo de barreira, educação essa que é representada, por exemplo, pelo movimento "Educação para todos" (UNESCO, 1994).

Entretanto, entendemos como um desafio, para a rede estadual de educação, se adaptar às reais necessidades da educação inclusiva, surgindo, assim, pela Secretaria de Educação Estadual - via Coordenação de Ensino Especial - o Programa Estadual de Educação para a diversidade numa perspectiva Inclusiva, que se destina a adequar todas as escolas para receberem alunos em situação de deficiência, pretendendo alcançar uma educação de alta qualidade sem excluir um único aluno (GOIÁS, 2004). O Programa de Inclusão demonstra a importância da convivência mútua entre todo o alunado:

Educando todos os alunos juntos, as pessoas com deficiência têm oportunidade de preparar-se para a vida em comunidade, os professores melhoram as suas habilidades profissionais e a sociedade toma a decisão consciente de funcionar de acordo com o valor social da igualdade para todas as pessoas, com os conseqüentes resultados de melhoria da paz social. Para conseguir realizar o ensino inclusivo, os professores em geral e especializados, bem como os recursos, devem aliar-se em um esforço unido e consciente. (STAINBACK; STAINBACK, 1999, p. 21)

Dessa maneira, é importante salientarmos que, para a escola ser "inclusiva", é necessária mobilização conjunta entre todos os agentes educacionais, envolvendo alunos, famílias e sociedade (STAINBACK; STAINBACK, 1999 apud STONE; COLLICOTT, 1994), havendo, 
A educação inclusiva na percepção dos professores ...

prioritariamente, uma atenção especial às diferenças, por exemplo, por meio de uma equipe qualificada de apoio aos estudantes e professores (assistência médica, psicológica, material didático específico para cada deficiência, tradutores - para alunos surdos etc.).

Tão relevante quanto isso, é que o professor esteja preparado para lidar com as diferentes necessidades de aprendizagem de cada aluno, inclusive os deficientes, e o locus inicial em que ele deve adquirir esses fundamentos é a formação inicial, ou seja, seu curso de graduação. É preciso considerar a formação do professor para a educação inclusiva como parte integrante do processo de formação geral, e não como um apêndice dos seus estudos ou um complemento. Mais do que isso, é importante que o professor adquira uma visão crítica sobre o assunto, pois ele é que será o responsável pela seleção curricular nas escolas e deverá se adaptar quanto aos conteúdos, práticas avaliativas e atividades de ensino e aprendizagem. Dessa maneira, para que tenhamos uma mudança paradigmática na educação inclusiva, o primeiro a ser mudado é o professor (HOFFMAN, 2004).

Tiballi (2003) coloca que há três elementos fundantes na educação inclusiva, sendo eles: o aluno, o professor e o conhecimento; para o professor deve haver qualificação profissional de maneira que ele saiba distinguir todas as diferentes formas de aprender que os alunos apresentam em uma mesma sala de aula. E, sob essa perspectiva de Tiballi (2003), não deve existir uma "educação inclusiva", pois não existem excluídos na escola, mas, sim, pessoas com diferentes necessidades de aprendizagem, e é para essas diferenças que o professor deve estar preparado. Dessa forma, a qualificação ideal do professor, que deve estar baseada na superação da racionalidade técnica (SCHÖN, 1998) e fundamentada em princípios de investigação e reflexão (SCHÖN, 1997), representa o fortalecimento da educação como um todo, pois viabiliza a crença de que os próprios professores podem desenvolver novas alternativas e competências (NÓVOA, 1992), estando libertos do discurso que não lhes pertence, adquirindo, dessa maneira, autonomia e sua própria voz (BAKHTIN, 1981). E sob a ótica da educação inclusiva, nos deparamos com o ensino de ciências, o qual defendemos para todas as pessoas, independentemente da situação econômica, social, física ou cultural a que elas pertençam.

Como resultado da democratização da ciência e de seus aparatos tecnológicos na vida humana, o ensino de ciências passa a ser considerado de crucial importância, já que o cidadão necessita, cotidianamente, tomar decisões que envolvam assuntos científicos (SANTOS; SCHNETZLER, 2003; FENSHAM, 2002). A importância do estudo de ciências deve-se, sobretudo, ao fato de possibilitar, à pessoa, o desenvolvimento de uma visão crítica sobre a realidade que a cerca, podendo, assim, utilizar seu conhecimento adquirido no cotidiano, analisar diferentes situações e ter condições para avaliar assuntos de importância na determinação de sua qualidade de vida (CACHAPUZ et al., 2005).

Dessa maneira, acreditamos que o ensino de ciências é essencial na educação para a cidadania, já que a participação efetiva na sociedade deve ser feita de modo racional, tendo o cidadão necessidades educativas especiais ou não - situação essa, viabilizada pelos próprios Parâmetros Curriculares Nacionais (BRASIL, 1998), que se fundamentam no princípio da igualdade: "do reconhecimento dos direitos humanos e o exercícios dos direitos e deveres da cidadania" (BRASIL, 1998, p. 76). Assim como em todas as outras áreas do conhecimento, o professor de ciências (Química, Física e Biologia) deve estar preparado para lidar com as diferenças dos alunos em sala de aula, inclusive com aqueles com necessidades educativas especiais, e, por isso, a importância de se discutirem as políticas educacionais de formação inicial de professores de ciência. 
Entretanto, destacamos que, para essa realidade se efetivar, os cursos de licenciatura em ciências devem estar preparados para formar professores para inclusão, ou seja, os professores formadores devem ser os primeiros a se prepararem, com vistas a que só serão formados profissionais aptos para inclusão se os próprios formadores tiverem percepção sobre o assunto. A questão é mais profunda do que apenas atender alunos com necessidades especiais ou advindos de realidades diversas, é necessário redefinição de conceitos, além de, também, possuir conhecimentos específicos sobre a realidade inclusiva.

Por isso, partimos do pressuposto de que as concepções dos professores formadores acerca da inclusão influenciam às dos professores em formação inicial. Além disso, as concepções sobre inclusão do corpo docente de uma instituição resultará (ou não) em políticas de formação para a inclusão nos cursos de licenciatura, já que são os professores que apresentam papéis essenciais no funcionamento das estruturas educacionais, como elaboração do Projeto Pedagógico de Curso (PPC) e responsabilidade em ministrar as disciplinas (O’DONUGHUE; CHALMERS, 2000).

Destacamos, ainda, que a importância de os professores pensarem sobre a educação inclusiva não advém apenas do fato de que são políticas instituídas pelo governo, mas sim, como assinalado anteriormente, da preocupação de serem formados professores reflexivos, capazes de interpretarem, compreenderem e, o mais importante de tudo, questionarem (SCHON, 1998). Assim, objetivamos investigar a concepção dos professores formadores de licenciados em Química, de uma Instituição de Ensino Superior Pública (IES) do estado de Goiás, sobre políticas de inclusão, já que seria relevante entender como eles pensam para, a partir daí, serem tomadas novas atitudes.

\section{Metodologia}

Para este estudo, foi utilizado um questionário com escala do tipo Likert (THOMAS; NELSON, 2002), com 25 afirmações orientadoras, em que os participantes respondem de acordo com o seu grau de concordância à mesma (acordo, desacordo ou parcial). A análise do questionário se fez a partir do grau de adequação das respostas ao esperado de uma visão apropriada de inclusão, de acordo com as concepções vigentes (STAINBACK; STAINBACK, 1999). O questionário abordou, essencialmente, dimensões sobre a educação inclusiva, tais como: as ideias do mesmo sobre educação inclusiva, o grau de aceitação e conhecimento sobre inclusão, condições necessárias para realização de inclusão, entre outros. O Projeto Pedagógico de Curso (PPC) dessa IES foi analisado a fim de se verificar o que há de oficial nas políticas do curso sobre educação inclusiva. Também foi feita uma entrevista semiestruturada - gravada em áudio - com o representante da coordenação do curso de Química, que foi transcrita e analisada sob uma perspectiva qualitativa.

\section{Resultados e discussão}

O curso de licenciatura em Química da IES investigada possui um corpo docente com sete professores, que receberam o questionário e tiveram um prazo definido para devol- 
A educação inclusiva na percepção dos professores ...

vê-lo. Todos os professores devolveram o material no tempo solicitado. Desse total de professores, três são somente licenciados em Química, um é licenciado e bacharel em Química, e três são bacharéis em Química. Todos têm mais de um ano de experiência na área de ensino, possuem mais de trinta anos de idade e são doutores na área técnica, com exceção de um único professor que tem mestrado na área de ensino.

Não foi possível realizar a entrevista com o coordenador do curso, de maneira que o vice-coordenador do curso se prontificou a fazê-la. A coordenação foi entrevistada por ser a representação, em teoria, da vontade dos demais membros do grupo, já que todas as questões devem ser votadas pelos outros professores, não devendo haver decisões isoladas. O professor, denominado nas transcrições por $\mathrm{VC}$, foi questionado sobre questões relativas à formação inicial dos licenciandos em Química do CaJ - UFG, e sua relação com a educação inclusiva e o PPC, já que esse é o documento que oficializa como será o currículo do curso.

No PPC, o perfil do profissional desejado é de caráter humanístico, para o qual são explicitadas habilidades no âmbito de expressões oral e escrita, com flexibilidade intelectual e:

Visão abrangente do papel do educador no desenvolvimento de uma consciência cidadã como condição para a criação de uma sociedade mais justa e democrática; [...]; Visão crítica dos problemas educacionais brasileiros e capacidade de propor soluções adequadas. (UNIVERSIDADE FEDERAL DE GOIÁS, 2007, p. 8)

Essas características constantes no PPC, de que o professor formado deve ter uma consciência cidadã para uma sociedade mais justa e democrática, além de demonstrar ciência dos problemas educacionais brasileiros, inclusive propondo soluções, fazem-nos refletir sobre o professor reflexivo e formado para a inclusão. Em contraponto a isso, o discurso da coordenação não salientou esses aspectos que estão presentes no currículo escrito, visto que, ao ser questionado sobre qual o perfil do licenciado desejado pela instituição, o professor (VC) salienta a importância de um profissional que domine os conteúdos de química e consiga desenvolvê-los tecnicamente. O discurso não apresenta traços de uma educação para lidar com as diferentes realidades de aprendizagem:

2. VC: [...] "Então o perfil do professor tem que ser aquele que tem capacidade de conduzir alguns conceitos fundamentais. Os conceitos fundamentais que eu entendo é o aluno pelo menos conseguir identificar algumas ligaçoes químicas, montar algumas pequenas estruturas e trabalhar alguns tipos de reaçöes voltadas à realidade do aluno né, porque não adianta a gente querer sofisticar demais. Agora a formação do professor, aquilo que ele vai trabalhar também não significa que nós vamos ensinar só as coisas básicas pra ele. O curso em si, ele é um curso de quimica, então ele tem que trabalhar conceitos mais aprofundados. Na esperança de que os professores consigam abstrair desses conceitos, mecanismos para conseguir trabalhar coisas mais fundamentais no ensino médio. [...]"

Essa realidade pode ser consequência da própria formação do professor entrevistado, que talvez não esteve pautada na formação para a cidadania, já que os bacharéis tendem a 
apresentar uma visão mais técnica do assunto. No que concerne ao fato de os profissionais formados na instituição serem capazes de trabalharem em uma sala de aula inclusiva baseados na formação inicial que tiveram, VC respondeu:

20. VC: "No momento não. Isso aí é uma coisa que nós precisamos ser sinceros. Até porque essa prática ou essa informação nos chegou há uns dois meses, mesmo sendo uma lei um pouco mais velha. A universidade demorou muito pra nos passar essa exigência. E hoje, hoje... nós temos condição de preparar muito bem, dentro daquilo que eu falei no inicio, pra trabalhar com pessoas sem algum tipo de deficiência. Ou pelo menos não com uma deficiência grave. Deficiência auditiva, deficiência visual... e não é o curso de química, é nenhum curso daqui que vai estar preparado pra preparar o aluno pra isso. Nesse momento, com o processo em andamento como ele está. Pode ser que ele vá se adaptar na frente."

Percebe-se que o professor relaciona a educação inclusiva apenas com alunos deficientes, e não a educação voltada para todos os grupos de pessoas excluídas da escola. E ainda, relaciona o fato da não-preparação para educação inclusiva como consequência de falta de preparo dos próprios professores formadores.

Assim, parece haver relação entre não haver formação inicial para a educação inclusiva nessa instituição com as percepções dos professores sobre esse assunto. Para isso, as concepções dos professores foram consideradas por meio do questionário. A pontuação total do mesmo é de 33 pontos, contabilizando-se que uma visão adequada da educação inclusiva seria dada por uma pontuação mínima de 15 pontos; entre nove e 14 pontos, uma visão parcialmente adequada (regular), e, abaixo de oito pontos, uma visão inadequada. A Figura 1 esboça o grau de adequação dos professores à educação inclusiva.

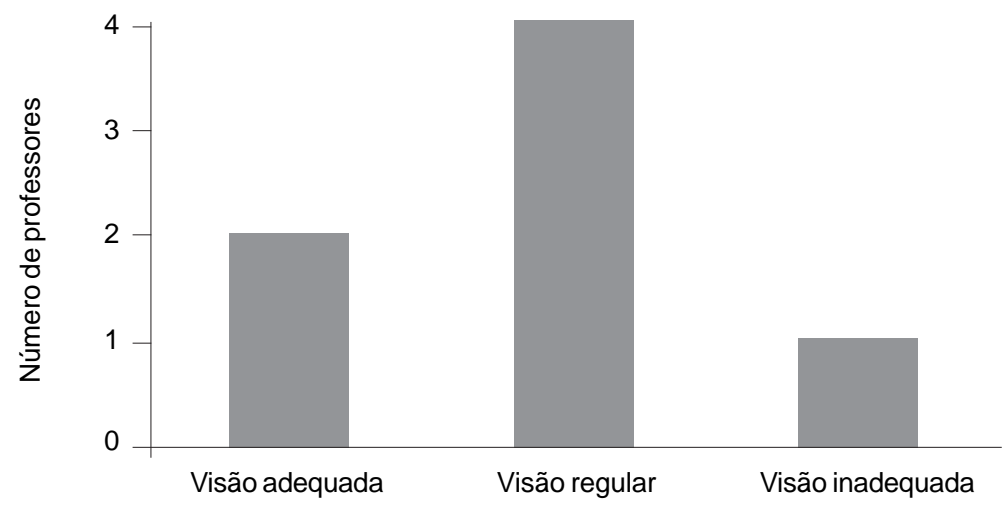

Figura 1. Grau de adequação dos professores em relação à educação inclusiva. 
É interessante perceber que os dois professores que possuem visão adequada da educação inclusiva são os licenciados. Acreditamos que a licenciatura proporciona, ao sujeito, uma visão crítica da educação, fato este que, teoricamente, colabora para percepções dos professores dentro da universidade, seja em relação à educação inclusiva ou regular, já que lidam diretamente com alunos. Em contraponto, os cursos de bacharelado - que priorizam uma visão técnica e não humanista, mas com formação para trabalhos de pesquisa em laboratório ou para o mercado de trabalho - talvez formem professores bacharéis com informações menos detalhadas sobre a educação inclusiva. No entanto, a opinião entre os professores é um pouco diferente, já que no tocante à afirmação "Os professores universitários também deveriam ter uma formação em licenciatura, já que lidam diretamente com sala de aula", apenas dois concordaram com a mes$\mathrm{ma}$, três discordaram e dois concordaram parcialmente, o que pode demonstrar que acreditam que o curso de licenciatura não é fundamental para se lecionar em Ensino Superior.

Quanto à educação inclusiva, os professores deveriam responder como consideram seu conhecimento em relação à inclusão; dos sete professores, quatro afirmaram que não possuem um bom nível de conhecimento em relação à inclusão, dois acreditam ter um nível intermediário de conhecimento e, apenas um, afirmou possuir um bom nível de conhecimento em relação à inclusão. Entretanto, ao serem indagados sobre o interesse em participar de um programa de formação para educação inclusiva, apenas dois se dispuseram, embora não explicitassem um tema em especial que achariam proveitoso.

Dessa maneira, questionamos o porquê de professores universitários não terem interesse em participar de discussões sobre inclusão, já que essa seria uma alternativa viável para o fortalecimento da qualidade da educação proporcionada aos alunos, por meio da construção de novos conhecimentos e o contato com uma nova realidade para aqueles que ainda não o tiveram com nenhum tipo de discussão conceitual sobre o tema. Salientamos, entretanto, que um dos motivos que pode ser plausível a essa situação é a falta de tempo, já que os professores precisam se dedicar à preparação de aulas, dar aulas, fazer pesquisa, publicar, orientar, ter projetos de extensão na comunidade, e, ainda, serem avaliados por tudo o que, em teoria, devem produzir - e, assim, estão sempre ocupados.

Vale ressaltar ainda, que a formação profissional docente é um processo contínuo, com data marcada para o início, mas nunca para o final. E seria ideal que todos os professores fossem convidados a refletir sobre sua própria prática, sendo pesquisadores de sua própria ação; e, por isso, foram feitas algumas afirmações de cunho reflexivo.

$\mathrm{Na}$ afirmação "Eu me sinto confortável se precisar receber um aluno com necessidades educativas especiais", apenas um professor afirmou que está de acordo com a afirmação, enquanto todos os demais não concordaram, ou concordaram apenas em parte. Esse fato pode indicar que o curso ainda não tem preparo para receber alunos com necessidades educativas especiais. Fato esse que pode ser percebido na estrutura de outros cursos, não só no de Química, como o próprio VC afirmou no turno 20 transcrito acima, já que a ideia de inclusão da Universidade é relativamente nova, e a adaptação a mudanças leva um tempo.

Essa característica dos professores ainda pode ser interligada com as respostas para a afirmação: "Um aluno com necessidades educativas especiais deve freqüentar escolas especiais, já que precisam de técnicas de ensino adequadas e professores capacitados essencialmente para isso", já que apenas dois discordaram da afirmação, e o restante concordou plenamente, ou em parte. 
Vilela-Ribeiro, E. B.; Benite, A. M. C.

A partir das reflexões realizadas, percebe-se que o curso de Química em questão ainda tem um longo caminho a percorrer até se adaptar às políticas de inclusão. Entretanto, a Universidade e os cursos de formação de professores não devem trilhar sozinhos esse caminho; ações de respaldo do Governo devem existir, priorizando a contratação de novos professores, estimulando o surgimento de pesquisas na área da educação inclusiva e reduzindo as várias obrigações dos professores.

Destaca-se, ainda, que o fator mais importante é o aspecto volitivo, que pode ser viabilizado com mais discussões, e, mais ainda, com o próprio tempo.

\section{Considerações finais}

O estudo apresentou alguns dados que permitem a reflexão sobre o importante papel que a Universidade desempenha na formação de futuros profissionais para a educação inclusiva. Os alunos saem da Universidade como profissionais "aptos" para o magistério, entretanto, se deparam com uma realidade para qual não foram preparados.

Constata-se a existência de argumentos de que a Universidade não prepara esses profissionais para a inclusão porque os próprios formadores não tiveram contato com esse assunto - o que não é caracterizado como pejorativo, mas como uma realidade dos profissionais formados em anos anteriores às políticas de incentivo à inclusão. E o que acontece é que a questão não é resolvida e a culpa é sempre de outro, e não de nós mesmos.

O discurso dos professores aponta para a aceitação da educação inclusiva, mas estes ainda não se sentem preparados para tal, e a principal dificuldade consiste em como preparar os professores formadores. 
A educação inclusiva na percepção dos professores ...

\section{Referências}

BAKHTIN, M. M. The dialogic imagination. Austin: University of Texas Press, 1981.

BRASIL. Ministério da Educação e Cultura. Secretaria de Educação Especial. Dados da Educação Especial no Brasil. Brasília: MEC/INEP, 2006.

Ministério da Educação e do Desporto. Secretaria de Educação Fundamental.

Parâmetros curriculares nacionais. Brasilia: MEC/SEF, 1998. 10 v.

Ministério da Educação. Secretaria da Educação Fundamental. Lei n. 9.394, de 20 de dezembro de 1996. Disponível em: <http://portal.mec.gov.br/seesp/arquivos/pdf/ lei9394_ldbn2.pdf>. Acesso em: 7 nov. 2008.

CACHAPUZ, A.; GIL-PEREZ, D.; CARVALHO, A.M.P.; PRAIA, J.; VILCHES, A. (Orgs.). A necessária renovação do ensino de ciências. São Paulo: Cortez, 2005.

DECLARAÇÃO Universal dos Direitos Humanos. Disponível em: <http://www.onubrasil.org.br/documentos_direitoshumanos.php>. Acesso em: 7 nov. 2008.

FENSHAM, P. J. Time to change drivers for scientific literacy. Canadian Journal of Science, Mathematics and Technology Education, Toronto, v. 2, n. 1, p. 9-24, 2002.

GOIÁS. Superintendência de Ensino Especial. Secretaria de Educação. Programa Estadual de Educação para a diversidade numa perspectiva inclusiva no estado de Goiás, Brasil. Goiânia: Secretaria de Educação, 2004.

HOFFMANN, J. M. L. Avaliar para promover: as setas do caminho. 6. ed. Porto Alegre: Mediação, 2004.

NÓVOA, A. Formação de professores e prática docente. In: NÓVOA, A. (Org.). Os professores e sua formação. 3. ed. Lisboa: Dom Quixote, 1992. p. 93-114.

O'DONOGHUE, T. A.; CHALMERS, R. How teachers manage their work in inclusive classrooms. Teaching and teacher education, London, v. 16, n. 8, p. 889-904, 2000.

SANTOS, W. L. P.; SCHNETZLER, R. P. Educação em Química: compromisso com a cidadania. Ijuí: Editora Unijuí, 2003.

SCHÖN, D. A. El profesional reflexivo: como piensan los profesionales cuando actúan. Barcelona: Paidós, 1998.

Formar professores como profissionais reflexivos. In: NÓVOA, A. (Org.). Os professores e sua formação. Lisboa: Dom Quixote, 1997. p. 79-81.

STAINBACK, S.; STAINBACK, W. Inclusão: um guia para educadores. Porto Alegre: Artmed, 1999.

STONE, J.; COLLICOTT, J. Supportive inclusive education: creating lawers of suport. In: INTERNATIONAL CONFERENCE EXCELLENCE AND EQUITY IN EDUCATION, 1., 1994, Toronto. Abstracts... Toronto, 1994. p. A-12. 
Vilela-Ribeiro, E. B.; Benite, A. M. C.

THOMAS, J. R.; NELSON, J. K. Métodos de pesquisa em atividades físicas. Porto Alegre: Artmed, 2002.

TIBALLI, E. F. A. Estratégias de inclusão frente à diversidade social e cultural na escola. In: LISITA, V. M. S. S.; SOUSA, L. F. E. C. P. (Orgs.). Políticas educacionais, práticas escolares e alternativas de inclusão escolar. Rio de Janeiro: DP\&A, 2003. p. 195-208.

UNESCO. Declaração de Salamanca sobre princípios políticos e práticas na área das necessidades educativas especiais: aprovado por aclamação na cidade de Salamanca, em 10 de junho de 1994. Disponível em: <http://unesdoc.unesco.org/images/0013/001393/ 139394por.pdf>. Acesso em: 6 nov. 2008.

UNIVERSIDADE FEDERAL DE GOIÁS. Projeto pedagógico do curso de Química: habilitação licenciatura. Goiânia: UFG, 2007.

Artigo recebido em julho de 2010 e aceito em outubro de 2010. 